\title{
Subchronic Rolipram Delivery Activates Hippocampal CREB and Arc, Enhances Retention and Slows Down Extinction of Conditioned Fear
}

\author{
Barbara Monti', Chiara Berteotti' and Antonio Contestabile*,I \\ 'Department of Biology, University of Bologna, Bologna, Italy
}

\begin{abstract}
Rolipram, a type IV-specific phosphodiesterase inhibitor, is known to improve memory under various learning tasks. Moreover, Rolipram treatments have been shown to increase expression and phosphorylation of a key factor for hippocampal memory consolidation, the CAMP-dependent response element-binding protein, CREB. However, the exact correlation between hippocampal CREB phosphorylation and memory improvement induced by Rolipram has not yet been determined in a CREB-dependent type of hippocampal-related learning in normogenic, intact rodents. Here, we report that subchronic Rolipram delivery by using osmotic minipumps increased the basal rat hippocampal expression and phosphorylation of CREB, as well as the expression of the CAMPdependent, memory-related protein, Arc. In parallel, the same treatment improved memory consolidation of conditioned fear. Furthermore, the increase of CREB phosphorylation and Arc expression consequent to the learning experience was enhanced in Rolipram-treated rats, compared to controls. By evaluating the time course of memory extinction over 10 days after the initial learning test, we also observed significant slowing down of the memory extinction rate in Rolipram-treated rats. This effect could be attributed to CREB phosphorylation and memory having been initially higher, as osmotic minipumps stopped to release Rolipram the first day after the initial learning test. Our data define the conditions through which the pharmacological manipulation of hippocampal CREB expression and activation result in memory amelioration in normogenic, intact animals. These results are relevant for the study of molecular correlates of memory, and may also be important in view of the efforts to design new pharmacological treatments, targeting the CREB pathway and leading to enhancement of learning and memory, even in the absence of patent neuropathology.

Neuropsychopharmacology (2006) 31, 278-286. doi:I0.1038/sj.npp. I 3008I3; published online 29 June 2005
\end{abstract}

Keywords: rat; hippocampus; CREB activity; Arc expression; conditioned fear learning; memory consolidation; memory extinction

\section{INTRODUCTION}

From Aplysia to mammals, the cellular cascade triggered by cAMP is involved in memory formation and consolidation (Poser and Storm, 2001; Wang and Storm, 2003). A prominent role for cAMP has been demonstrated in longterm potentiation (LTP) and in hippocampus-dependent memory, through activation of the cAMP-dependent protein kinase A (PKA), phosphorylation of the transcription factor cAMP-dependent response element-binding protein (CREB) and stimulation of CREB-dependent gene expression (Frey et al, 1993; Bourtchuladze et al, 1994; Lonze and Ginty, 2002; Nguyen and Woo, 2003; Ahi et al, 2004). In particular, the role of CREB activation through its phosphorylation on serine-133 in memory consolidation

*Correspondence: Dr A Contestabile, Department of Biology, University of Bologna, Via Selmi 3, 40126 Bologna, Italy, Tel: + 39 05। 2094 I34, Fax: + 39 05 I 2094286, E-mail: acontest@alma.unibo.it Received 28 February 2005; revised 26 April 2005; accepted 24 May 2005

Online publication: I June 2005 at http://www.acnp.org/citations/ Npp060105050137/default.pdf has been studied in rodents after two types of single-trial hippocampus-dependent tasks: contextual learning and inhibitory avoidance (Impey et al, 1998; Taubenfeld et al, 1999). Recent data on transgenic mice overexpressing the type 1 adenylyl cyclase in the forebrain have suggested that the process of memory extinction also could depend on increased CREB activation (Wang et al, 2004).

Phosphodiesterase (PDE) inhibitors, such as the selective type IV PDE inhibitor Rolipram (Schneider, 1984; Weishaar et al, 1985), have been used to increase the brain level of cAMP. The consequent increase of cAMP-dependent cellular pathways has antidepressant action and reverses memory deficits caused by antagonists of NMDA receptor and other drugs (Fujimaki et al, 2000; Itho et al, 2004; Imanishi et al, 1997; Zhang et al, 2000, 2004; Zhang and O’Donnell, 2000; Sato et al, 2004; Vitolo et al, 2002). It also improves memory after ischemia and febrile seizures in a mouse model of Rubinstein-Taybi syndrome (Nagakura et al, 2002; Bourtchouladze et al, 2003; Chang et al, 2003). The dependence of LTP and hippocampus-dependent memories on the cAMP signaling cascade suggested that drugs enhancing this pathway could improve learning and 
reinforce memory. Rolipram, indeed, induced persistent LTP in hippocampal slices and increased long-term memory retention when injected at low dosage in mice, shortly before submitting them to a hippocampus-dependent memory task (Barad et al, 1998; Navakkode et al, 2004). Noticeably, in these experiments, high Rolipram dosage delivered before training was ineffective, while both low and high doses improved memory when administered immediately after training (Barad et al, 1998). In this study, however, no attempt was performed to correlate the Rolipram-dependent memory improvement with the induction of the cAMP/PKA/P-CREB pathway in the mice hippocampus. Recent experiments on a mouse model for Alzheimer's disease not only demonstrated improvement of hippocampus-dependent memory after acute administration, but also suggested that long-term systemic administration of the drug could result in amelioration of memory deficit for at least 2 months after ending the treatment (Gong et al, 2004). In these experiments, the correlation of the memory improvement with hippocampal P-CREB was only demonstrated concerning the learning-impaired transgenic mice, as no effect of Rolipram administration was observed in wild-type mice. In other experiments, prolonged Rolipram administration increased hippocampal CREB expression at the mRNA level (Nibuya et al, 1996), as well as its phosphorylation in relation to adult neurogenesis in hippocampal dentate gyrus (Nakagawa et al, 2002a, b; Fujioka et al, 2004).

Notwithstanding the increasing importance of manipulating the cAMP-dependent cascade in studies on memory (Giorgi et al, 2004; Zhang et al, 2005), the exact correlation between Rolipram effects on CREB activation and memory consolidation/extinction has not yet been precisely determined. Furthermore, the expression of other memoryrelated genes as a consequence of the increased cAMP cascade activation has not been addressed using pharmacological approaches to activate CREB. Among cAMPdependent memory-related genes, it is particularly interesting the activity-regulated cytoskeletal-associated protein Arc/Arg 3.1. Arc is an immediate early gene, whose expression has found to be altered in different hippocampus-dependent learning tasks (Guzowski et al, 2000, 2001; Montag-Sallaz and Montag, 2003; Inoue et al, 2005), and whose inhibition impairs LTP and memory (Guzowski et al, 2000). Even if Arc does not contain any CRE consensus sequence in its promoter region, it has been demonstrated that its expression is regulated by the cAMP/PKA/CREB pathway (Waltereit et al, 2001). Moreover, BDNF-induced hippocampal LTP in vivo has been shown to upregulate Arc expression, in parallel with CREB activation (Ying et al, 2002).

We report here that, at variance with acute administration, steady Rolipram delivery through osmotic minipumps increases basal CREB expression and phosphorylation in the rat hippocampus. When Rolipram-treated rats were trained in a conditioned fear task, increase of hippocampal CREB phosphorylation was significantly higher than in vehicle-treated animals and, in parallel, memory retention was improved and memory extinction slowed down. Moreover, Arc behaved similarly to CREB in its expression in response to subchronic Rolipram treatment as well as to the learning experience.

\section{MATERIALS AND METHODS}

\section{Animals and Surgery}

Male Wistar rats were purchased from Harlan Italy at 7 weeks of age and used when they were 10 weeks old. All animals were maintained on a $12: 12 \mathrm{~h}$ light/dark cycle and given food and water ad libitum. The experiments were carried out in accordance with the requirements of the Italian and European Community laws on the use of animals for experimental purposes. The experimental protocols were approved by a local bioethical committee and the experiments were performed under the supervision of a veterinary commission.

Rolipram (Sigma, St Louis, MO) was delivered either through i.p. injections or through osmotic minipumps (model 2001, Alzet, Cupertino, CA), implanted subcutaneously in the back of animals under light ether anesthesia. The actual concentration of Rolipram for pump delivery was calculated on a weight basis, in such a way as to obtain a steady release of $0.5 \mathrm{mg} / \mathrm{kg} /$ day for 7 days. Vehicle-treated animals received injection of saline containing $2 \%$ DMSO, or were implanted with pumps containing the Rolipram vehicle ( $50 \% \mathrm{DMSO})$. For the pump delivery experiments, a further control group was constituted of sham-operated rats.

\section{Apparatus and Testing Procedure}

Training sessions were carried on $2 \mathrm{~h}$ after the last, or unique, Rolipram i.p. injection, or at the end of the fifth day after pump implantation. Learning tests were performed $24 \mathrm{~h}$ later. The training chamber for fear conditioning (Ugo Basile, Comerio, VA, Italy) consisted of a microprocessorcontrolled unit, made by a $28 \times 21 \times 21 \mathrm{~cm}^{3}$ cage with the 20 stainless steel bar floor connected to a shock generator. The transparent ceiling allowed the rat to be observed. Rats were trained with a context-tone presentation which has been demonstrated to strongly involve hippocampus (Phillips and LeDoux, 1994; Rogelj et al, 2003). The conditioned stimulus consisted of a tone $(70 \mathrm{~dB}, 670 \mathrm{~Hz})$ and the unconditioned stimulus of an electrical foot shock $(0.7 \mathrm{~mA}$ for $2 \mathrm{~s}$ ) delivered immediately after the tone.

Animals were divided into two groups: the control group, in which the animals explored the context $(3 \mathrm{~min})$, followed by the conditioned stimulus and by another period $(4 \mathrm{~min})$ spent in the chamber; the conditioned group in which animals explored the chamber $(3 \mathrm{~min})$ before to be exposed to both the conditioned stimulus and the shock and remained there for additional $4 \mathrm{~min}$. After the training, each animal was returned to its home cage and the apparatus was cleaned with $70 \%$ ethanol. To test memory retention, each animal was introduced in the same apparatus $24 \mathrm{~h}$ after training and, after $1 \mathrm{~min}$, the same tone used for the training session was delivered.

The time spent in freezing by the animal during a fixed time after the tone was assumed as the index of conditioned fear, based on the ability to remember and associate the aversive event with both the tone and the context in which it was presented during the training (Sanders et al, 2003; Woolf et al, 1999, 2001). The freezing behavior, defined as the lack of any movement besides respiration, was scored by 
two independent observers, every $5 \mathrm{~s}$ during a 2-min interval. At the end of testing, animals were killed by decapitation and the hippocampus was immediately dissected and frozen at $-80^{\circ} \mathrm{C}$ until used for Western blot analysis. The extinction trials were performed on groups of rats trained and tested as described above and subsequently tested again, with the same procedure, every other day during a 10-days interval (Corcoran and Maren, 2001; Fischer et al, 2004).

\section{Western Blotting}

Protein samples were homogenized in $100 \mathrm{mM}$ Tris containing $200 \mathrm{mM} \mathrm{NaCl}, 10 \%$ glycerol, $2 \mathrm{mM} \mathrm{NaF}, 2 \mathrm{mM} \mathrm{Na}{ }_{4} \mathrm{P}_{2} \mathrm{O}_{7}$, $2 \mathrm{mM}$ DTT, $1 \mathrm{mM}$ EDTA, $1 \mathrm{mM}$ benzamidine, $0.1 \mathrm{mM}$ $\mathrm{Na}_{3} \mathrm{VO}_{4}, 1 \mathrm{mM}$ pepstatine, $10 \mathrm{mg} / \mathrm{ml}$ trypsin inhibitor, $10 \mathrm{mg} / \mathrm{ml}$ aprotinin, $10 \mathrm{mg} / \mathrm{ml}$ leupeptin, and $10 \mathrm{mM}$ PMSF at $\mathrm{pH} 7.4$ (all chemicals were from Sigma Chemical, St Louis, MO, USA). After $15 \mathrm{~min}$ lysis in ice, samples were centrifuged at $20,500 \mathrm{~g}$ for $15 \mathrm{~min}$. After determination of protein content (Lowry et al, 1951), equal amounts of protein $(30 \mu \mathrm{g})$ from each sample were resolved in SDSPAGE before electroblotting. Membranes were incubated with antibodies against CREB, independently from its phosphorylation state or phosphorylated on serine-133 (Upstate Biotechnology, Lake Placid, NY, USA), or Arc (Santa Cruz Biotechnology, Inc., Santa Cruz, CA) or $\beta$-actin (Sigma), then with an HRP-linked secondary antibody (Amersham) and visualized by ECL (Amersham). The films were scanned and densitometry was performed using the software 'NIH Image'. Quantitation of CREB, P-CREB, and Arc was performed with reference to the invariant cytoskeletal protein, $\beta$-actin, as an additional loading control. Additionally, the P-CREB/CREB ratio was calculated in order to precisely estimate changes in the phosphorylation state of CREB in relation to the pharmacological manipulation and the learning experience.

\section{Statistical Analysis}

All results were subjected to statistical analysis with oneway and two-way ANOVA (variables: treatment and training), followed by Bonferroni's post hoc comparison test and Student's $t$-test, in order to evaluate the significance of the differences.

Figure I Time-course analysis of acute Rolipram administration ( $3 \mathrm{mg} / \mathrm{kg}$ ) on phosphorylated CREB or total CREB and on Arc in rat hippocampus. Western Blot analysis was performed on hippocampi from rats treated with a single i.p. injection of Rolipram $(3 \mathrm{mg} / \mathrm{kg})$ and collected at different time points (from 2 to $18 \mathrm{~h}$ ) after the injection. Their relative densitometries revealed that this dose of Rolipram induced a short-lasting ( $2-4 \mathrm{~h}$ ), but statistically significant increase in phosphorylated CREB (a) and in $\operatorname{Arc}$ (c) levels, but not in total CREB, that is, independently from its phosphorylation state (b). Both P-CREB and Arc return to basal level within $6 \mathrm{~h}$. Data are expressed as the percentage relative to controls (vehicletreated animals) for each protein level, after normalization for the $\beta$-actin content in each sample. Each bar represents the mean \pm SEM of 3-5 animals. $* * * *<0.00$ I, *** $p<0.0$ I, * $p<0.05$ compared to the respective controls. Bonferroni's test after one-way ANOVA.

\section{RESULTS}

\section{Rolipram Affects Hippocampal CREB and Arc}

In order to evaluate the feasibility of obtaining a long-term increase of CREB phosphorylation by using acute Rolipram injection, we started delivering single Rolipram doses, based on the amount of drug previously demonstrated to be able to increase hippocampal levels of cAMP in rats (Giorgi et al, 2004). Acute i.p. administration of Rolipram at a dose of
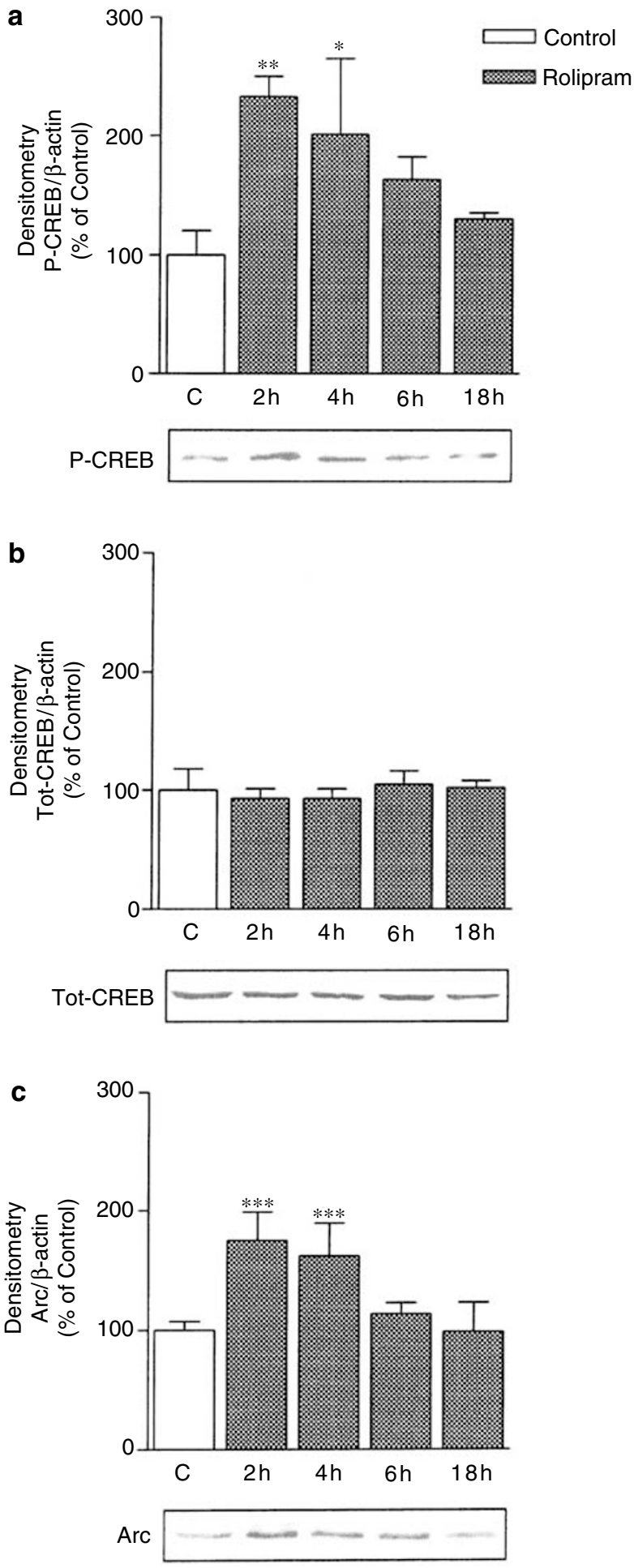
$0.3 \mathrm{mg} / \mathrm{kg}$, which was previously shown not to change hippocampal cAMP levels (Giorgi et al, 2004), had no effect on hippocampal CREB phosphorylation from 2 to $6 \mathrm{~h}$ after injection (data not shown). A higher $(3 \mathrm{mg} / \mathrm{kg}$ ) dosage of Rolipram, which was previously demonstrated to be able to increase cAMP levels up to $24 \mathrm{~h}$ after administration (Giorgi et al, 2004), only resulted in a short-lasting $(2-4 \mathrm{~h})$ increase of hippocampal P-CREB (Figure 1a) and Arc levels (Figure 1c), while the expression of CREB protein was unchanged (Figure 1b). Both levels of P-CREB and Arc returned to control values within $6 \mathrm{~h}$ after drug administration (Figure 1a, c). Administration of the same dosage of Rolipram split into two daily injections for 5 days gave a similar transitory induction of CREB phosphorylation and Arc expression after the last drug injection (data not shown). Both these last treatments resulted in no significant memory improvement in the fear-conditioning test, as rats trained $2 \mathrm{~h}$ after the unique, or the last, Rolipram injection and tested $24 \mathrm{~h}$ later exhibited the same freezing score of vehicle-treated animals (Table 1). Previous studies have demonstrated a sedative effect of Rolipram shortly (15$60 \mathrm{~min}$ from injection) after acute administration (Silvestre et al, 1999a, b; Zhang and O'Donnel, 2000). No such effect was observed in our experiments, both at the time of training ( $2 \mathrm{~h}$ after administration) and testing $(24 \mathrm{~h}$ after administration).

In order to test whether continuous administration of Rolipram could result in long-lasting increase of CREB phosphorylation, we used controlled delivery through

Table I Effects of Single or Repeated Rolipram Injections on Conditioned Fear Memory Retention

\begin{tabular}{lcclll}
\hline & \multicolumn{2}{c}{ Vehicle } & & \multicolumn{2}{c}{ Rolipram } \\
\cline { 2 - 3 } \cline { 5 - 6 } & Control & Conditioned & & Control & Conditioned \\
\hline Single injection & $2.4 \pm 3.7$ & $82.2 \pm 15.7^{* * * *}$ & & $3.8 \pm 3.8$ & $81.8 \pm 18.2^{* * * * *}$ \\
Repeated injections & $3.6 \pm 2.3$ & $83.5 \pm 16.2^{* * * *}$ & & $2.8 \pm 3.9$ & $80.9 \pm 17.5^{* * * * *}$ \\
\hline
\end{tabular}

Rats treated either with a single $(3 \mathrm{mg} / \mathrm{kg}$ ) or with repeated (twice a day for 5 days, $3 \mathrm{mg} / \mathrm{kg} /$ day) Rolipram injections were trained for conditioned fear $2 \mathrm{~h}$ after the unique or last injection and tested for memory retention $24 \mathrm{~h}$ later. No differences were observed between the conditioned groups of Rolipram- or vehicle-treated animals following either the single or the repeated treatment. Data are expressed as the mean of freezing percentage \pm SEM in control and conditioned groups of vehicle- and Rolipram-treated rats. Each value represents the mean \pm SEM of 3-4 animals. $* * * * 0.001$, compared to the respective control groups; Bonferroni's test after two-way ANOVA.

Figure 2 Effect of subchronic Rolipram $(0.5 \mathrm{mg} / \mathrm{kg} /$ day $)$ administration through osmotic minipumps on phosphorylated CREB or total CREB and on Arc levels in rat hippocampus. Western blot analysis were performed on the hippocampi from sham-operated or vehicle- or Rolipram-treated rats and collected after 5 days from minipump implant. Densitometries of rat hippocampal level of phosphorylated CREB (a), of total CREB (b) and of Arc (c) revealed that subchronic Rolipram delivery induced a significant increase in the steady level of both CREB expression and phosphorylation, as well as that of Arc expression. Data are expressed as the percentage relative to controls (sham-operated animals) of each protein level, after normalization for the $\beta$-actin content in each sample. Each bar represents the mean \pm SEM of $3-5$ animals. $* p<0.05$ compared to sham-operated rats. Bonferroni's test after one-way ANOVA. osmotic minipumps. This procedure of continuous delivery of Rolipram $(0.5 \mathrm{mg} / \mathrm{kg} /$ day $)$ had no apparent side effects and significantly increased the steady level of CREB expression and phosphorylation (Figure 2a, b), as determined in the hippocampi of rats killed 5 days after pump implantation, compared to sham-operated and vehicletreated animals. As the increase in phosphorylated protein
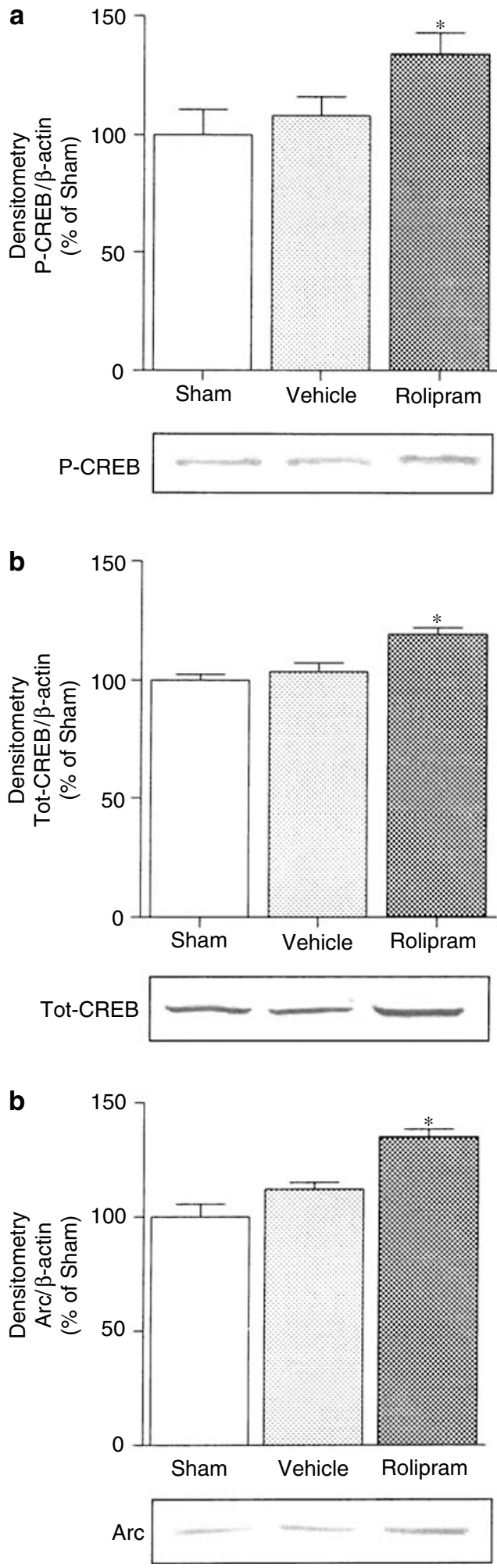
was larger than the increase in native protein expression, the ratio of $\mathrm{P}-\mathrm{CREB} / \mathrm{CREB}$ was also significantly increased (vehicle: $100 \pm 1.3 \%$; Rolipram: $113.5 \pm 2.6 \%$; $p<0.05$ ). An equivalent increase was also noticed for Arc protein expression in this group of Rolipram-treated rats (Figure 2c).

\section{Increased Hippocampal CREB Activation and Arc Expression Correlate with Stronger Memory Retention}

We performed training for conditioned fear 5 days after pump implantation and tested its retention $24 \mathrm{~h}$ later, when the pump was still releasing Rolipram. Upon conditions of continuous delivery, Rolipram had no patent sedative effect on rats, as also demonstrated by the lack of freezing observed in Rolipram- compared to vehicle-treated animals in the absence of conditioned fear training. As expected, both vehicle- and Rolipram-treated rats of the conditioned groups exhibited much higher freezing levels, compared to controls (Figure 3). In addition, notwithstanding the nearly maximal level of the behavioral response in control animals, the freezing score of Rolipram-treated rats was slightly, but significantly increased compared to vehicle-treated animals (Figure 3). No differences in the freezing score were observed between vehicle-treated and sham-operated rats (data not shown). In the hippocampi of these rats, killed immediately after the retention test, we determined the level of CREB phosphorylation and Arc expression, both known to be induced in hippocampus-dependent memory consolidation (Impey et al, 1998; Taubenfeld et al, 1999; Guzowski et al, 2000, 2001). As the subchronic Rolipram treatment induced a significant increase in CREB protein level, as shown before (Figure 2), the results were expressed as the ratio $\mathrm{P}$-CREB/total $\mathrm{CREB}$, in order to isolate the

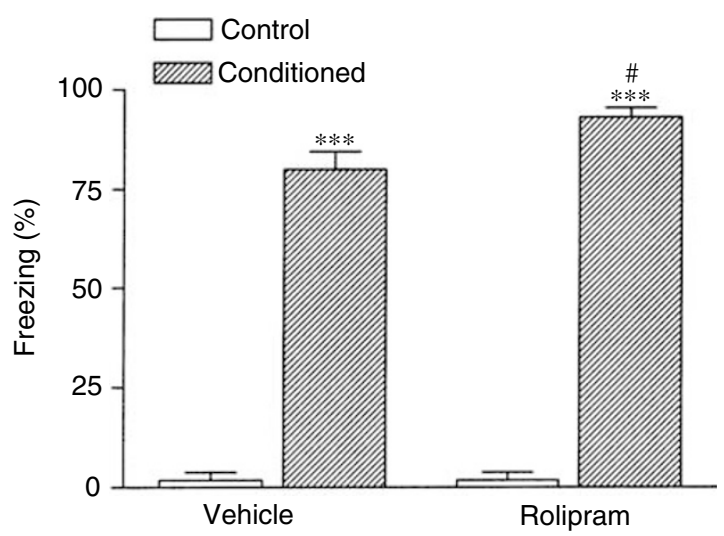

Figure 3 Effect of subchronic Rolipram treatment through osmotic minipumps on conditioned fear. Rats subchronically treated either with vehicle or with Rolipram $(0.5 \mathrm{mg} / \mathrm{kg} /$ day $)$ through osmotic minipumps were trained for conditioned fear 5 days after the implant and tested for memory retention $24 \mathrm{~h}$ later. Freezing percentage was used as index of conditioned fear memory retention. The conditioned groups of both vehicle- and Rolipram-treated rats showed a much higher freezing percentage compared to their respective controls and the freezing score of the conditioned group of Rolipram-treated animals was significantly increased compared to the conditioned group of vehicle-treated rats. Each bar represents the mean \pm SEM of $4-10$ animals. **** $p<0.001$, compared to the respective control groups; ${ }^{*} p<0.05$ compared to the conditioned group of vehicle-treated rats. Bonferroni's test after two-way ANOVA. increase in CREB phosphorylation related to the combined effects of learning and pharmacological treatment. The PCREB/CREB ratio, a known index of CREB activation (Gong et al, 2004), was significantly increased in the hippocampus of fear-conditioned rats compared to controls, thus demonstrating the expected correlation between learning and activation of hippocampal CREB (Figure 4a). In addition, the subchronic Rolipram treatment additionally activated hippocampal CREB, as demonstrated by the significant increase in the $\mathrm{P}$-CREB/CREB ratio found in drug- compared to vehicle-treated rats (Figure 4a). Hippocampal Arc expression behaved similarly to the index of CREB activation, as it was increased in the hippocampus in relation to learning, and a further increase was shown by Rolipram-treated rats (Figure $4 \mathrm{~b}$ ). No differences in
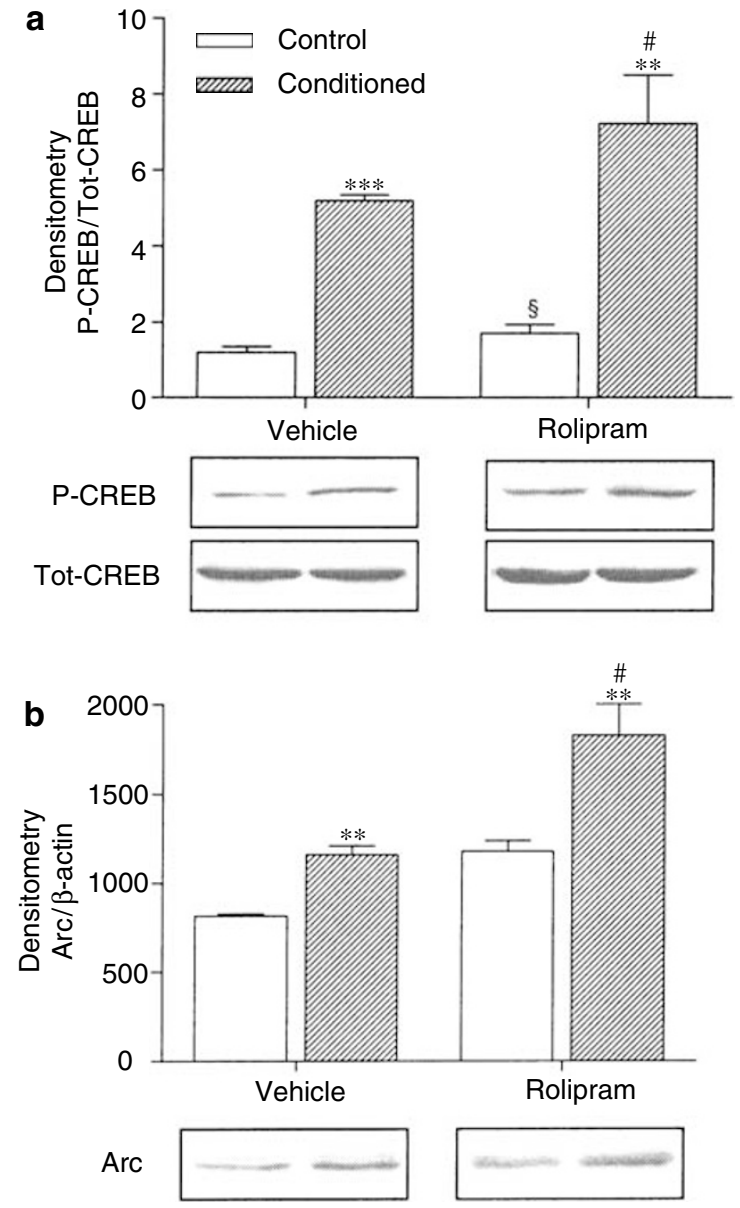

Figure 4 Effect of subchronic Rolipram treatment on CREB and Arc activation following induction of conditioned fear. Western Blot analysis was performed on the hippocampi from rats treated either with vehicle or with Rolipram $(0.5 \mathrm{mg} / \mathrm{kg} /$ day $)$ through osmotic minipumps, trained for conditioned fear 5 days after the implant and tested for memory retention $24 \mathrm{~h}$ later. Quantification through densitometries revealed that the phospho-CREB/total CREB (a) as well as the Arc/ $\beta$-actin (b) ratio were significantly increased in conditioned rats compared to controls and that, in parallel with memory retention, subchronic Rolipram treatment further increased both values compared to vehicle-treated rats. Each bar represents the mean \pm SEM of $4-10$ animals. **** $p<0.001$, *** $p<0.01$ compared to the respective controls; ${ }^{\#} p<0.05$ compared to the conditioned group of vehicle-treated rats. Bonferroni's test after two-way ANOVA. 
P-CREB/CREB ratio or Arc expression were observed between vehicle-treated and sham-operated rats (data not shown).

\section{Stronger Memory Consolidation Induced by Rolipram Slows Down Subsequent Memory Extinction}

Parallel groups of rats were used to assess the effect of stronger initial memory and higher CREB activation on the rate of memory extinction, evaluated by testing the animals every other day from the second to the 10th day after the initial learning test. Although Rolipram-treated rats showed extinction of conditioned fear memory, their rate of memory extinction was significantly slowed down, compared to both sham-operated and vehicle-treated rats (Figure 5). This could not be attributed to long-term persistence of increased P-CREB/CREB ratio and Arc expression after the ending of the pharmacological treatment. No differences were, indeed, noticed after extinction tests in the hippocampi of previously Rolipram-treated, vehicle-treated or sham-operated rats (Figure 6a, b).

\section{DISCUSSION}

We have subchronically delivered steady amounts of Rolipram through osmotic minipumps and this resulted in increased CREB and P-CREB basal levels in rat hippocampus. Upon training in a conditioned fear task, these rats displayed an increased freezing response and an increased level of the P-CREB/total CREB ratio in their hippocampus. Another cAMP-dependent protein involved

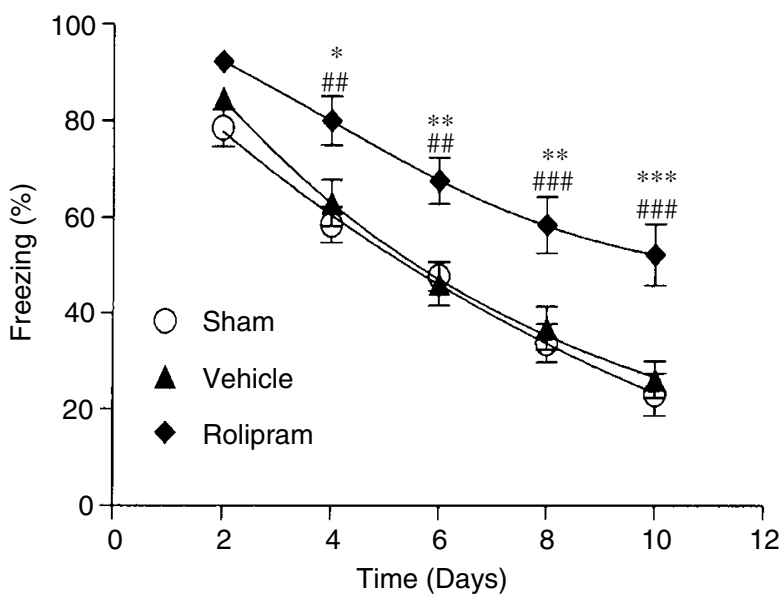

Figure 5 Effect of subchronic Rolipram treatment through osmotic minipumps on conditioned fear memory extinction rate. Rats subchronically treated with Rolipram through osmotic minipumps $(0.5 \mathrm{mg} / \mathrm{kg} /$ day $)$ were trained for conditioned fear 5 days after the implant, tested $24 \mathrm{~h}$ later and further tested every other day during the following 10 days. Freezing percentage at different days $(2-10)$ after the initial learning test has been used as index of conditioned fear memory retention in the conditioned rat groups. Although subchronic Rolipram-treated rats $(\bullet)$ exhibited memory extinction, its rate was significantly slowed down compared to both shamoperated $(O)$ and vehicle-treated $(\boldsymbol{\Lambda})$ animals. Each point represents the mean + SEM of five animals. $* p<0.05$, ** $p<0.01$, **** $p<0.001$ compared to vehicle-treated rats at the same day; ${ }^{\# \#} p<0.01,{ }^{\# \#} p<0.00$ I compared to sham-operated rats on the same day. Bonferroni's test after two-way ANOVA. in hippocampal memory, Arc, was also increased in its basal and learning-induced levels in the hippocampus of Rolipram-treated rats. These concomitant effects were only observed in rats treated subchronically through osmotic minipumps, indicating that attainment of an increased steady level of expression and activity was essential in the enhancement of the behavioral response. Furthermore, when the time-course of memory extinction was studied at different times after the initial test and after the ending of drug delivery, previously Rolipram-treated rats exhibited slower extinction rate of the acquired memory.

Previous reports separately demonstrated that Rolipram or other PDE inhibitors were able to: (i) increase hippocampal CREB expression or activity (Nibuya et al, 1996; Nakagawa et al, 2002a, b; Fujioka et al, 2004; Itho et al, 2004); (ii) improve hippocampus-dependent memory (Barad et al, 1998; Navakkode et al, 2004); or (iii) reverse various types of memory deficits (Imanishi et al, 1997; Zhang et al, 2000, 2004; Zhang and O'Donnell, 2000;
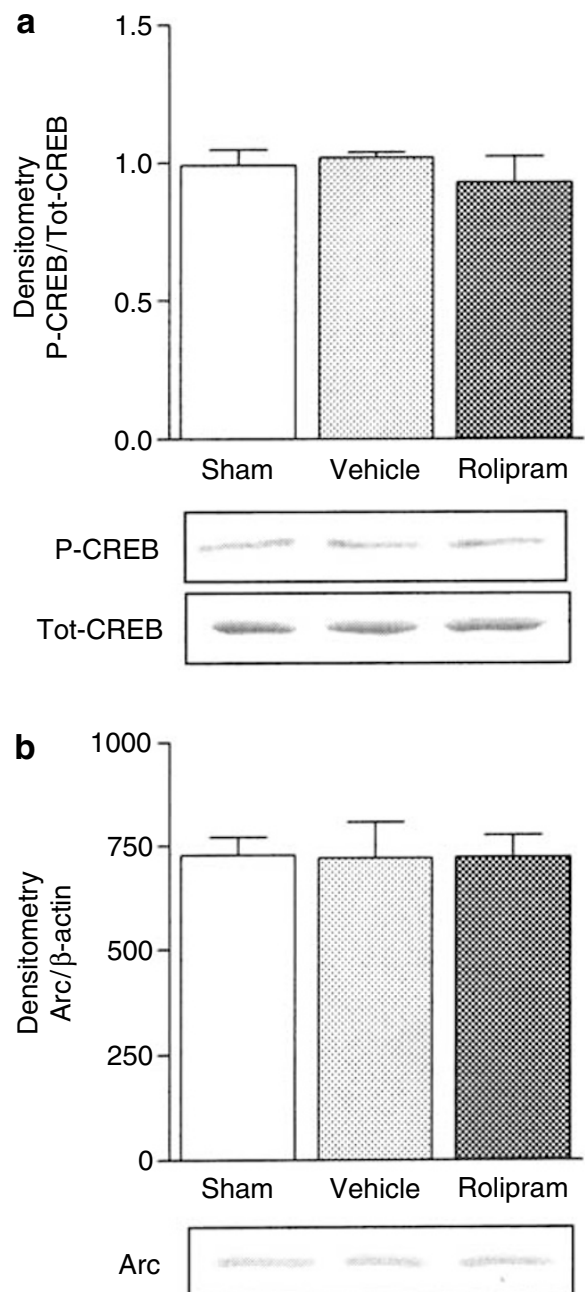

Figure 6 Effect of subchronic Rolipram treatment through osmotic minipumps on P-CREB, total-CREB, and Arc level at the end of the memory extinction experiment. Western blot analysis was performed on hippocampi from the same groups of Figure 5. Densitometries revealed that there was no difference either in the phospho-CREB/total-CREB (a) or in the $\mathrm{Arc} / \beta$-actin (b) ratio. Each bar represents the mean \pm SEM of three animals. 
Nagakura et al, 2002; Bourtchouladze et al, 2003; Chang et al, 2003; Sato et al, 2004). Recently, it was also shown that low dosage of Rolipram administered for 3 weeks to an Alzheimer mouse model resulted in long-term recovery ( 2 months after the end of the treatment) of hippocampal CREB phosphorylation and memory, while having no such effects on wild-type animals (Gong et al, 2004). Sizeable effects temporally related to the actual drug treatment were only observed in normal mice by using much higher doses $(1.25 \mathrm{mg} / \mathrm{kg} /$ day for 15 days; Nakagawa et al, 2002a, b; Fujioka et al, 2004). Concerning rats, biochemical effects on the hippocampal cAMP system and restoration of behavioral impairment in normogenic, intact animals has been only reported for substantially higher doses of Rolipram (Giorgi et al, 2004; Nagakura et al, 2002; Egawa et al, 1997).

Conditioned fear, while apparently a simple form of learning, is actually a rather complex phenomenon from a neurobiological point of view. The exact role of the hippocampus in the process leading to memory retention in this learning task has been discussed (Sanders et al, 2003). Recent data point at the hippocampus as the central memory structure for fear conditioning, not only concerning the spatial representation of the context but also the other elements used to remind the whole contextual situation, such as the tone (Quinn et al, 2002; Sanders et al, 2003). The central role of the hippocampal-related contextual recognition in our experiments was strongly supported by the fact that rats trained by exposure to tone and shock immediately after entering the training chamber, without being allowed to preventively explore the context, displayed only very low freezing, as previously described by others (Fanselow, 1986, 1990; Westbrook et al, 1994). We observed, in addition, that these animals showed no increase in hippocampal CREB phosphorylation when assayed $24 \mathrm{~h}$ after training (data not shown).

Extinction of contextual fear memory has been recently studied in transgenic mice that overexpress type- 1 adenylyl cyclase in their forebrain (Wang et al, 2004). These authors found a trend similar to the one described here, with transgenic mice showing a slower memory extinction rate compared to wild-type animals (Wang et al, 2004). However, in transgenic animals, higher levels of CREB phosphorylation are constitutively present (Wang et al, 2004). In our model, instead, Rolipram release, and the consequent increase of CREB phosphorylation, ended shortly (approximately $24 \mathrm{~h}$ ) after the initial memory test. Memory extinction after Pavlovian fear conditioning is not a simple process of progressive forgetting, but rather a new learning experience during which the animal shifts from conditioned stimulus-unconditioned stimulus to a new conditioned stimulus-no unconditioned stimulus association (Rescorla, 2001; Suzuki et al, 2004). There is also evidence that the memory extinction signaling pathways are different from those involved in memory consolidation (Lin et al, 2003; Szapiro et al, 2002; Fischer et al, 2004). Our data demonstrate through a novel experimental procedure of subchronic PDE inhibition the pivotal role of hippocampal CREB activation in memory consolidation (Bourtchuladze et al, 1994; Impey et al, 1998; Taubenfeld et al, 1999, 2001a, b; Athos et al, 2002). At the same time, our results do not support a direct role of CREB activation in memory extinction, as the slowing down of the extinction process occurred in our model when Rolipram was not released any more. The pharmacological upregulation of CREB activation was, therefore, absent during the extinction period, as the subchronic Rolipram treatment did not result in any long-term increase of P-CREB/CREB ratio (or Arc expression as well). From these results, it could be concluded that it is the stronger initial memory, associated to higher initial levels of CREB activation, that is important in slowing down the memory extinction rate, possibly by counteracting the mechanisms of consolidation of the new learning.

Arc is an immediate early gene whose expression is highly regulated by synaptic activity, in LTP and memory consolidation (Lyford et al, 1995; Guzowski et al, 2000, 2001; Lee et al, 2004). The present data are in line with these previous results and strengthen the functional link between Arc expression and CREB activation. Arc has been shown to be regulated by the CAMP/PKA/CREB cascade, even if its promoter does not contain any CRE consensus elements, thus suggesting an indirect way of regulation (Waltereit et al, 2001). Our data not only demonstrate that Arc is induced by conditioned fear learning, but also strengthen the role of the cAMP signaling pathway in Arc induction in hippocampus-dependent memory.

In conclusion, our data define the conditions through which the pharmacological manipulation of hippocampal CREB expression and activation result in parallel enhancement of memory consolidation and slowing down of memory extinction in normogenic, intact animals. In addition to their relevance for the study of molecular correlates of memory, the present results may be important in view of the efforts to design new pharmacological treatments, targeting the CREB pathway and leading to enhancement of learning and memory, even in the absence of patent neuropathology (Barco et al, 2003; Jackson and Ramaswami, 2003).

\section{ACKNOWLEDGEMENTS}

The present work was funded by a grant of the Italian Ministry for University and Research (PRIN grant scheme) to AC. The skilful technical help of Miss Monia Bentivogli is gratefully acknowledged.

\section{REFERENCES}

Ahi J, Radulovic J, Spiess J (2004). The role of hippocampal signaling cascades in consolidation of fear memory. Behav Brain Res 149: 17-31.

Athos J, Impey S, Pineda VV, Chen X, Storm DR (2002). Hippocampal CRE-mediated gene expression is required for contextual memory formation. Nat Neurosci 5: 1119-1120.

Barad M, Bourtchouladze R, Winder DG, Golan H, Kandel E (1998). Rolipram, a type IV-specific phosphodiesterase inhibitor, facilitates the establishment of long-lasting long-term potentiation and improves memory. Proc Natl Acad Sci USA 95: 15020-15025.

Barco A, Pittenger C, Kandel ER (2003). CREB, memory enhancement and the treatment of memory disorders: promises, pitfalls and prospects. Expert Opin Ther Targets 7: 101-114.

Bourtchuladze R, Frenguelli B, Blendy J, Cioffi D, Schutz G, Silva AJ (1994). Deficient long-term memory in mice with a targeted mutation of the cAMP-responsive element-binding protein. Cell 79: 59-68. 
Bourtchouladze R, Lidge R, Catapano R, Stanley J, Gossweiler S, Romashko D et al (2003). A mouse model of Rubinstein-Taybi syndrome: defective long-term memory is ameliorated by inhibitors of phosphodiesterase 4. Proc Natl Acad Sci USA 100: 10518-10522.

Chang YC, Huang AM, Kuo YM, Wang ST, Chang YY, Huang CC (2003). Febrile seizures impair memory and cAMP responseelement binding protein activation. Ann Neurol 54: 706-718.

Corcoran KA, Maren S (2001). Hippocampal inactivation disrupts contextual retrieval of fear memory after extinction. J Neurosci 21: $1720-1726$

Egawa T, Mishima K, Matsumoto Y, Iwasaki K, Iwasaki K, Fujiwara M (1997). Rolipram and its optical isomers, phosphodiesterase 4 inhibitors, attenuated the scopolamine-induced impairments of learning and memory in rats. Jpn J Pharmacol 75: 275-281.

Fanselow MS (1986). Associative vs topographical accounts of the immediate shock freezing deficit in rats: implications for the response selection rules governing species specific defensive reactions. Learn Motivation 17: 16-39.

Fanselow MS (1990). Factors governing one trial contextual conditioning. Animal Learn Behav 18: 264-270.

Fischer A, Sananbenesi F, Schrick C, Spiess J, Radulovic J (2004). Distinct roles of hippocampal de novo protein synthesis and actin rearrangement in extinction of contextual fear. $J$ Neurosci 24: 1962-1966.

Frey U, Huang YY, Kandel ER (1993). Effects of cAMP simulate a late stage of LTP in hippocampal CA1 neurons. Science 260: 1661-1664.

Fujimaki K, Morinobu S, Duman RS (2000). Administration of a cAMP phosphodiesterase 4 inhibitor enhances antidepressantinduction of BDNF mRNA in rat hippocampus. Neuropsychopharmacology 22: 42-51.

Fujioka T, Fujioka A, Duman RS (2004). Activation of cAMP signaling facilitates the morphological maturation of newborn neurons in adult hippocampus. J Neurosci 24: 319-328.

Giorgi M, Modica A, Pompili A, Pacitti C, Gasbarri A (2004). The induction of cyclic nucleotide phosphodiesterase 4 gene (PDE4D) impairs memory in a water maze task. Behav Brain Res 154: 99-106.

Gong B, Vitolo OV, Trinchese F, Liu S, Shelanski M, Arancio O (2004). Persistent improvement in synaptic and cognitive functions in an Alzheimer mouse model after Rolipram treatment. J Clin Invest 114: 1624-1634.

Guzowski JF, Lyford GL, Stevenson GD, Houston FP, McGaugh JL, Worley PF et al (2000). Inhibition of activity-dependent arc protein expression in the rat hippocampus impairs the maintenance of long-term potentiation and the consolidation of longterm memory. J Neurosci 20: 3993-4001.

Guzowski JF, Setlow B, Wagner EK, McGaugh JL (2001). Experience-dependent gene expression in the rat hippocampus after spatial learning. A comparison of the immediate-early genes Arc, c-fos, and zif268. J Neurosci 21: 5089-5098.

Imanishi T, Sawa A, Ichimaru Y, Miyashiro M, Kato S, Yamamoto $\mathrm{T}$ et al (1997). Ameliorating effects of Rolipram on experimentally induced impairments of learning and memory in rodents. Eur J Pharmacol 321: 273-278.

Impey S, Smith DM, Obrietan K, Donahue R, Wade C, Storm DR (1998). Stimulation of cAMP response element (CRE)-mediated transcription during contextual learning. Nat Neurosci 1: 595-601.

Inoue K, Fukazawa Y, Ogura A, Inokuchi K (2005). Twodimensional neural activity mapping of the entire population of hippocampal CA1 pyramidal cells responding to fear conditioning. Neurosci Res 51: 417-425.

Itho T, Tokumura M, Abe K (2004). Effects of Rolipram, a phosphodiesterase 4 inhibitor, in combination with imipramine on depressive behavior, CRE-binding activity and BDNF level in learned helplessness rats. Eur J Pharmacol 498: 135-142.
Jackson T, Ramaswami M (2003). Prospects of memory-modifying drugs that target the CREB pathway. Curr Opin Drug Discov Devel 6: 712-719.

Lee JL, Everitt BJ, Thomas KL (2004). Independent cellular processes for hippocampal memory consolidation and reconsolidation. Science 304: 839-843.

Lin CH, Yeh SH, Lu HY, Gean PW (2003). The similarities and diversities of signal pathways leading to consolidation of conditioning and consolidation of extinction of fear memory. J Neurosci 23: 8310-8317.

Lonze BE, Ginty DD (2002). Function and regulation of CREB family transcription factors in the nervous system. Neuron 35: 605-623.

Lowry OH, Rosenbrough NJ, Farr AL, Randall RJ (1951). Protein measurement with the Folin phenol reagent. J Biol Chem 193: 265-275.

Lyford GL, Yamagata K, Kaufmann WE, Barnes CA, Sanders LK, Copeland NG et al (1995). Arc, a growth factor and activityregulated gene, encodes a novel cytoskeleton-associated protein that is enriched in neuronal dendrites. Neuron 14: 433-445.

Montag-Sallaz M, Montag D (2003). Learning-induced arg 3.1/arc mRNA expression in the mouse brain. Learn Mem 10: 99-107.

Nakagawa S, Kim JE, Lee R, Chen J, Fujioka T, Malberg J et al (2002b). Localization of phosphorylated cAMP response element-binding protein in immature neurons of adult hippocampus. J Neurosci 22: 9868-9876.

Nakagawa S, Kim JE, Lee R, Malberg JE, Chen J, Steffen C et al (2002a). Regulation of neurogenesis in adult mouse hippocampus by cAMP and the cAMP response element-binding protein. J Neurosci 22: 3673-3682.

Nagakura A, Niimura M, Takeo S (2002). Effects of a phosphodiesterase IV inhibitor Rolipram on microsphere embolisminduced defects in memory function and cerebral cyclic AMP signal transduction system in rats. Br J Pharmacol 135: 17831793.

Navakkode S, Sajikumar S, Frey JU (2004). The type IV-specific phosphodiesterase inhibitor Rolipram and its effect on hippocampal long-term potentiation and synaptic tagging. J Neurosci 24: 7740-7744.

Nguyen PV, Woo NH (2003). Regulation of hippocampal synaptic plasticity by cyclic AMP-dependent protein kinases. Prog Neurobiol 71: 401-437.

Nibuya M, Nestler EJ, Duman RS (1996). Chronic antidepressant administration increases the expression of cAMP response element binding protein (CREB) in rat hippocampus. J Neurosci 16: $2365-2372$.

Phillips RG, LeDoux JE (1994). Lesions of the dorsal hippocampal formation interfere with background but not foreground contextual fear conditioning. Learn Mem 1: 34-44.

Poser S, Storm DR (2001). Role of $\mathrm{Ca}^{2+}$-stimulated adenylyl cyclases in LTP and memory formation. Int J Dev Neurosci 19: 387-394.

Quinn JJ, Oommen SS, Morrison GE, Fanselow MS (2002). Posttraining excitotoxic lesions of the dorsal hippocampus attenuate forward trace, backward trace, and delay fear conditioning in a temporally specific manner. Hippocampus 12: 495-504.

Rescorla RA (2001). Experimental extinction. In: Mowrer RR, Klein S (eds). Handbook of Contemporary Learning Theories. Erlbaum: Mahwah, NJ. pp 119-154.

Rogelj B, Hartmann CE, Yeo CH, Hunt SP, Giese KP (2003). Contextual fear conditioning regulates the expression of brainspecific small nucleolar RNAs in hippocampus. Eur J Neurosci 18: 3089-3096.

Sanders MJ, Wiltgen BJ, Fanselow MS (2003). The place of the hippocampus in fear conditioning. Eur $J$ Pharmacol 463: 217-223. 
Sato T, Tanaka K, Ohnishi Y, Teramoto T, Irifune M, Nishikawa T (2004). Inhibitory effects of group II mGluR-related drugs on memory performance in mice. Physiol Behav 80: 747-758.

Silvestre JS, Fernandez AG, Palacios JM (1999a). Effects of Rolipram on the elevated plus-maze test in rats: a preliminary study. J Psychopharmacol 13: 274-277.

Silvestre JS, Fernandez AG, Palacios JM (1999b). Preliminary evidence for an involvement of the cholinergic system in the sedative effects of Rolipram in rats. Pharmacol Biochem Behav 64: $1-5$.

Schneider HH (1984). Brain cAMP response to phosphodiesterase inhibitors in rats killed by microwave irradiation or decapitation. Biochem Pharmacol 33: 1690-1693.

Suzuki A, Josselyn SA, Frankland PW, Masushige S, Silva AJ, Kida $S$ (2004). Memory reconsolidation and extinction have distinct temporal and biochemical signatures. J Neurosci 24: 4787-4795.

Szapiro G, Galante JM, Barros DM, Levi de Stein M, Vianna MR, Izquierdo LA et al (2002). Molecular mechanisms of memory retrieval. Neurochem Res 27: 1491-1498.

Taubenfeld SM, Milekic MH, Monti B, Alberini CM (2001b). The consolidation of new but not reactivated memory requires hippocampal C/EBPbeta. Nat Neurosci 4: 813-818.

Taubenfeld SM, Wiig KA, Bear MF, Alberini CM (1999). A molecular correlate of memory and amnesia in the hippocampus. Nat Neurosci 2: 309-310.

Taubenfeld SM, Wiig KA, Monti B, Dolan B, Pollonini G, Alberini CM (2001a). Fornix-dependent induction of hippocampal CCAAT enhancer-binding protein (beta) and (delta) co-localizes with phosphorylated cAMP response element-binding protein and accompanies long-term memory consolidation. J Neurosci 21: 84-91.

Vitolo OV, Sant'Angelo A, Costanzo V, Battaglia F, Arancio O, Shelanski M (2002). Amyloid beta-peptide inhibition of the PKA/ CREB pathway and long-term potentiation. Reversibility by drugs that enhance cAMP signaling. Proc Natl Acad Sci USA 99: 13217-13221.

Waltereit R, Dammermann B, Wulff P, Scafidi J, Staubli U, Kauselmann $\mathrm{G}$ et al (2001). Arg3.1/Arc mRNA induction by $\mathrm{Ca}^{2+}$ and cAMP requires protein kinase $\mathrm{A}$ and mitogen-activated protein kinase/extracellular regulated kinase activation. J Neurosci 21: 5484-5493.

Wang H, Ferguson GD, Pineda VV, Cundiff PE, Storm DR (2004). Overexpression of type- 1 adenylyl cyclase in mouse forebrain enhances recognition memory and LTP. Nat Neurosci 7: 635-642.

Wang H, Storm DR (2003). Calmodulin-regulated adenylyl cyclases. Cross-talk and plasticity in the central nervous system. Mol Pharmacol 63: 463-468.

Weishaar RE, Cain MH, Bristol JA (1985). A new generation of phosphodiesterase inhibitors. Multiple molecular forms of phosphodiesterase and the potential for drug selectivity. J Med Chem 28: 537-545.

Westbrook RF, Good AJ, Kiernan MJ (1994). Effects of the interval between exposure to a novel environment and the occurrence of shock on the freezing responses of rats. $Q J$ Exp Psychol B 47: 427-446.

Woolf NJ, Milov AM, Schweitzer ES, Roghani A (2001). Elevation of nerve growth factor and antisense knockdown of TrkA receptor during contextual memory consolidation. J Neurosci 21: 1047-1055.

Woolf NJ, Zinnerman MD, Johnson GV (1999). Hippocampal microtubule-associated protein-2 alterations with contextual memory. Brain Res 821: 241-249.

Ying SW, Futter M, Rosenblum K, Webber MJ, Hunt SP, Bliss TV et al (2002). Brain-derived neurotrophic factor induces longterm potentiation in intact adult hippocampus: requirement for ERK activation coupled to CREB and upregulation of Arc synthesis. J Neurosci 22: 1532-1540.

Zhang HT, Crissman AM, Dorairaj NR, Chandler LJ, O'Donnell JM (2004). Inhibition of cyclic AMP phosphodiesterase (PDE4) reverses memory deficits associated with NMDA receptor antagonism. Neuropsychopharmacology 23: 198-204.

Zhang HT, Huang Y, Suvarna NU, Deng C, Crissman AM, Hopper $\mathrm{AT}$ et al (2005). Effects of the novel PDE4 inhibitors MEM1018 and MEM1091 on memory in the radial-arm maze and inhibitory avoidance tests in rats. Psychopharmacology, in press (originally published online Jan 26, 2005).

Zhang HT, O'Donnell JM (2000). Effects of Rolipram on scopolamine-induced impairment of working and reference memory in the radial-arm maze tests in rats. Psychopharmacology 150: 311-316.

Zhang HT, Zhao Y, Huang Y, Dorairaj NR, Chandler LJ, O’Donnell JM (2000). Inhibition of the phosphodiesterase 4 (PDE4) enzyme reverses memory deficits produced by infusion of the MEK inhibitor U0126 into the CA1 subregion of the rat hippocampus. Neuropsychopharmacology 29: 1432-1439. 